\title{
Optical coherence tomography: a new diagnostic technique in interventional cardiology
}

\author{
Marina Pavletić*, \\ Vesna Puklin \\ University of Zagreb School \\ of Medicine, University \\ Hospital Centre Zagreb, \\ Zagreb, Croatia
}

KEYWORDS: optical coherence tomography, interventional cardiology, stents, coronary artery disease. CITATION: Cardiol Croat. 2016;11(3-4):119. | DOI: http://dx.doi.org/10.15836/ccar2016.119

*ADDRESS FOR CORRESPONDENCE: Marina Pavletić, Klinički bolnički centar Zagreb, Kišpatićeva 12, HR-10000 Zagreb, Croatia. / Phone: +385-95-562-6804 / E-mail: marinapavletic@gmail.com ORCID: Marina Pavletić, http://orcid.org/0000-0002-1165-7097 • Vesna Puklin, http://orcid.org/0000-0001-6537-241X

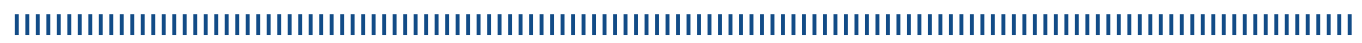

Optical coherence tomography (OCT) is a novel invasive imaging technique that produces high resolution intracoronary images. Its general principle of operation is similar to intravascular ultrasound, however OCT uses infrared light, not ultrasound. Using infrared light, optical coherence tomography enables detailed evaluation of coronary atherosclerotic plaques and of the vascular response to coronary interventional devices, such as new generation coronary stents. ${ }^{1}$

Optical coherence tomography can also be used as guide for coronary intervention. In the last years, the need for more precise information regarding coronary artery disease to achieve optimal treatment has seen intravascular imaging becoming an area of primary importance in interventional cardiology. OCT in this area has grown and is spreading. It benefits both therapeutic and research purposes and is also proving able to fill gaps in conventional invasive coronary imaging.
RECEIVED:

February 9, 2016

ACCEPTED:

February 20, 2016

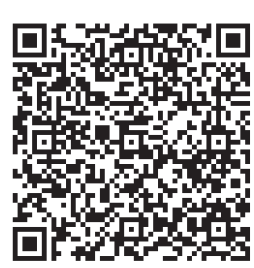

LITERATURE IIIIIIIIIIIIIIIIIIIIIIIIIIIIIIIIIIIIIIIIIIIIIIIIIIIIIIIIIIIIIIIIIIIIIIIIIIIIIIIIIIIIIIIIIIIIIIIIIII

1. Kashiwagi M, Liu L, Gardecki JA, Tearney GJ. Optical Coherence Tomography in Coronary Artery Disease: Toward Sub cellular Imaging. Austin J Clin Cardiolog. 2014;1(3):1019. 